\title{
Socio-cultural Factors in Second Language Learning: A Case Study of Adventurous Adult Language Learners
}

\author{
Burhan Ozfidan $^{* 1}$, Krisanna L. Machtmes ${ }^{2}$ and Husamettin Demir ${ }^{3}$ \\ ${ }^{I}$ Texas A\&M University, USA \\ ${ }_{3}^{2}$ Ohio University, USA \\ Inonu University, Turkey \\ "E-mail: b.ozfidan@tamu.edu
}

\begin{abstract}
Sociocultural theories consider language learning as a social pr actice examines students as active participants in the construction of learning processes. This study investigates sociocultural theories' central concepts, which includes peer interaction and feedback, private speech, and self-efficacy. The present study is a case study of twenty participants. The participants for this case study were from different nationalities that demonstrated a unique ability to learn languages long after the critical period. Data was collected through interviews and observations. The participant mentioned about the process and the challenges/ opportunities he experienced regarding second language learning. By analyzing the learning practices of other successful adult language learners, recurring patterns revealed similarities, which were then emphasized and elaborated in second language pedagogy.
\end{abstract}

Keywords: socio-cultural, language learning, language learner

\section{Introduction}

There a re several theories $w$ ithin the field of 1 inguistics that a ttempt to explain how pe ople 1 earn a second language. Regarding the act of learning, sociocultural theory has a universal view. In the field of second language learning (SLL) r esearch, sociocultural theories have be en extensively referred to (e.g. see Donato, 1994; Gutiérrez, 2003; Haas, 1996; Ohta, 2000; Swain, 1995; W arschauer \& Kern, 2000). Language, according to socio-cultural theorist Vygotsky (1962), comes out from cultural and social activity and only later becomes reconstructed as an individual, psychological phenomenon. In this way of thinking, SLL theory should be centered not so much on the process of learning new structures and sounds and then using them to communicate, but rather on the learner's participation in social activities such as having out-of-class conversations or talking to classmates and teachers. This study investigates sociocultural theories' central concepts, which are mentioned in second language research area, involving feedback and peer interaction, private speech, and self-efficacy.

\section{Significance and Purpose of the study}

Language learning is not all about learning the lexicon and the grammar of a spe cific language. It encompasses many other factors such as how knowledge of the language is transferred and how communication and interaction affect the process of language learning. Learning does not happen in vacuum. In order to be a successful and proficient language learner, the person needs to make use of all his/her 
cognitive and social skills to master the language. In this regard, the purpose of this study is to investigate how socio-cultural factors affect second language learning.

\section{Literature review}

Sociocultural theory examines students as a ctive participants in the construction of learning processes and considers language learning as a social practice. This study investigates sociocultural theory's central $\mathrm{c}$ oncepts, $\mathrm{w}$ hich include pe er interaction a nd f eedback, $\mathrm{s}$ caffolding, pr ivate s peech, a nd $\mathrm{s}$ elfefficacy.

Feedback is referred to as negative input. Since learners become aware of their errors through feedback they learn, feedback is very essential (Sato \& Lyster, 2012). According to the findings of Flor (2010), feedback is of great relevance while dealing with second language acquisition. Peer interaction through tasks is also an essential feature of com municative classrooms; therefore, successful SLA requires peer interaction. While working in pairs, students tend to write longer texts with more information than students w orking individually. P eer interaction c omplements teacher-fronted interaction by providing a context for greater opportunity for individual production, and practice and meaningful use of the target language (Philp, Walter, \& Basturkmen, 2010).

Peer interaction is very important in second language learning and active in reviews of work involving peer support during oral activities. Ohta, who is an expert in applied linguistics, has contributed much research in this area of socio-cultural theory. Ohta (1995) performed a study with seven adults learning Japanese as a se cond language and received results that illustrated effective peer scaffolding during oral collaboration. Learners used strategies such as repair and co-construction to assist their peers. Ohta ranked the strategies used in order of explicitness. Her study showed learners producing language they otherwise couldn't have without the collaboration of their peers. Ohta explains that the reason why this study was successful and important is that it illustrates the abilities that learners have while c ollaborating. F or a beginning s peaker, producing out put is di fficult and overwhelming, however the listener is not overwhelmed with attention demands such as grammar and has the ability to evaluate what is being said while being able to predict what will come next. For this reason, the collaboration between the listener and speaker is es sential in order to produce a productive learning environment.

Self-efficacy has a tremendous influence on s econd language learning. Clément, Dörnyei, and Noels (1994) asserted that self-efficacy indicates an individual's judgment of his/her skill to a chieve a specific action. In developing self-efficacy, learners' past achievements play a significant role; however, people also consider efficacy from observational experiences like observing peers. They should also consider e fficacy from $r$ einforcement, $p$ ersuasion, and e valuation by o thers, particularly pa rents or teachers. For instance, telling second language learners "you can do it!" or "you are doing fine!" encourages them to be more efficient learners. A failure may not have much impact when a strong sense of efficacy is developed. According to Oxford and Shearin (1994), most students feel lost in the language class since they do not have a pr imary be lief in their s elf- efficacy. Therefore, t eachers should help them improve a sense of self-efficacy by providing meaningful and achievable language tasks.

Private speech is another sociocultural factor. There are two functions in speech: self-oriented and communicative. The o vert, s elf-oriented spe ech is de noted as private speech, which is different from communicative speech. Private speech, according to Vygotsky (1981), is a type of speech that is addressed to oneself ( self-directed) though it is o ccasionally s poken loudly, a s oppos ed to external speech, which provides a social function and is intended to address other people. Lantolf (2000) indicates more on the concept by stating that via private speech "we ask ourselves questions, answer these questions, tell ourselves to interrupt a particular activity, tell ourselves we are wrong or that we cannot do something, and that we have completed a task" (p.15). Private speech ultimately develops into inner 
speech and becomes sub-vocal as the person cognitively develops. In a 1985 study, Wertsch's asserted that p rivate sp eech normally i ncludes e lliptical ut terances that are not en tirely sy ntactic. U tterances such as wait, what? next, no, I can "t are examples of private speech addressed to the self.

For this research study, the pa rticipants w ere ask ed to answer the qu estions $r$ egarding the process and the challenges/opportunities they experienced regarding second language acquisition. The following question was explored:

- What effects do the following socio-cultural factors have on the language development of highly successful language learner: peer feedback, private speech, and self-efficacy?

\section{Method}

The present study is a cas e study of twenty participants (Creswell, 1994). Data was collected through systematic interviews. The participants for this case study were from different nationalities, Iran, Chine, Japan, Azerbaijan, Egypt, and Turkey who demonstrated a unique ability to learn languages long after the critical period and who has been living in the US for about more then two years. The participants were a sked to a nswer que stions regarding the challenges/opportunities they e xperienced dur ing their language learning processes. In data analysis', the answers of the participants to the questions related with peer interaction and feedback, private s peech, and self-efficacy' the cen tral concepts of soc iocultural theory were analyzed to determine the similarities and differences between their answers and inferences were drawn based on these answers.

\section{Data Setting and Procedures}

The data was collected by means of interviews and observations. The researcher spent a month over the summer doing research with some of the participants in Romania. During this time, the researcher had a chance to live and work with them closely. The researcher was able to observe the participants' ability to learn a new language and record these observations. The participants were observed four times in a month. While the researcher was observing the participants, he took notes. In addition to these observations, interviews lasting approximately forty-five minutes each were conducted on learning second language. The first interviews centered on his family, community and travels, and were designed to elicit a biography. The second interviews focused on language acquisition, motivation, and identity. The third interview consisted of specific questions regarding peer interaction and feedback, private spe ech, and self-efficacy. All interviews w ere ta pe-recorded and transcribed. S ome of $t$ he i nterviews w ere c onducted over the phone and no tape recording was made. To supplement the observations and interviews, the researcher gathered relevant information from a website the participant has created which includes a brief autobiography and various reflections on education, culture, and language.

Interviews were conducted twenty times. Each lasted approximately forty-five minutes. The interviews were conducted at various places: the participant's house, at work, and the car. All of the interviews and most of the informal conversations were recorded. In these instances, notes were taken of the interactions between the participants and the people he interacted with. Informal que stions were asked of the participants in order to better understand his/her life here in the United States and to compare it with his/her life experiences in their countries.

\section{Data Analysis}

In this case study, the researchers used cross-case theme analysis. It involved reassembling the data depended on logical connections a mong categories (Creswell, 2003). Once the researchers had the data, he started analyzing. The purpose of the analysis was to confirm that the data were united in an attempt to understand the overall case or the contributing factors that influence the case. Analysis depended on understanding the data. In other words, the researchers read and re-read the text. The researchers listened to the tape recordings numerous times and wrote down any impressions about sociocultural fac- 
tors that he encountered he had as he went through the data. These impressions were useful while identifying themes.

Data analysis informally started during interviews and continued during transcription when recurring themes became evident. Once the transcriptions were available, analysis involved the identification of points that emerged from the interview and observations. The discussion ideally linked these themes explicitly to larger theoretical and practical issues.

\section{Findings}

When recurring themes became evident, data analysis began informally during interviews and continued during transcription. Once the transcriptions were available, analysis involved the identification of points that emerged from the interviews. The discussion ideally linked these themes explicitly to larger theoretical and practical issues.

\section{Peer interaction and feedback}

According to participants, throughout all their language experiences, working with peers had a major influence on their learning of a language. Peer interaction provided them good opportunities for their language learning because they tended to produce much spoken and written language. Also, one of the participants indicated that "receiving negative and positive feedback from his professor and correcting errors that the professor pointed out improved his second language." According to participants, peer interaction had a minor effect on the process of language learning. In most classes that were observed by the researcher, the interaction patterns were mostly teacher-student or student teacher. There were few communicative tasks, which required interaction with other peers. Most of $t$ he feedback that the researcher realized was mostly corrections done by teachers. The participants af firmed that such direct feedbacks hindered learners' language learning since they always afraid of making mistakes in class.

One of the participants who was an international faculty member at a US institution stated,

"As a t eenager, I us ed to go to an English language institute, which mainly focused on audiolingualism approach towards language learning. Much of the instruction was done by the teacher and he/she had a dominant role in the class. My classmates and I had to repeat the correct linguist forms and pronunciation of them. The teacher was a model for us and we had to perform as well as he/she did in class. Therefore, the type of interaction, which we experienced in the classes, was mostly teacher-student type. However, there were some occasions which students were assigned either pair works or group works. On those occasions I was more relaxed when I made mistakes. I think the reason of it was that I was not monitored by the teacher and I was not afraid that I would make a terrible mistake and my classmates would laugh at me. With my classmates, whenever one of us made mistakes we corrected each other. Our intention was mostly to help each other rather than competing for accuracy or fluency. In some situations when neither of us was sure about the correct answer, we used to check it either with other classmates or consult a dictionary and our textbooks. However, as I told before, just a minimum amount of time was devoted to peer or group work activities."

For this reason, the collaboration between the listener and speaker is essential in order to produce a productive learning environment.

\section{Self-efficacy}

The participants emphasized that they were usually in a positive mood during the period of learning a language to enhance their self-efficacy; however, negative moods diminished their language learning. For instance, one of the participants stated that when he was in the Philippines to learn English, he was 
in a negative mood for about a month because of cloudy weather. H e stated cloudy weather always gave him 'pessimistic feelings.' To avoid these feelings, the participant said that he usually took action like $\mathrm{w}$ atching ha ppy movies to minimize ne gative e motional $\mathrm{s}$ tates to help to strengthen his $\mathrm{s}$ elfefficacy beliefs. He said this was very helpful while learning English. According to participants, selfefficacy was de fined as the courage to speak up in class. The participants affirmed that they had the confidence in their linguistic abilities. However, in some cases, such as teachers' negative feedbacks, they retreated and lost their courage to perform well.

One of the participants who was an international $\mathrm{PhD}$ student in a US institution stated,

"I gained my self-efficacy in learning English by placing achievable goals for myself. I remember one of my language teachers told us once that learning a second or foreign language is like an ocean and there is no end for it. I placed realistic goals for myself and tried to master a reasonable amount of language materials before I embarked on learning more. In my view, part of the level of self-efficacy, which I gained, is due to my high level of $\mathrm{m}$ otivation i $\mathrm{n} l$ earning the $\mathrm{E}$ nglish $\mathrm{l}$ anguage. $\mathrm{H}$ aving $\mathrm{s}$ trong i nternal de sires to achieve a g oal can make pe rson mange the obstacles and difficulties in a much better way. As I have al ways been so interested in learning English as a f oreign language in Iran, I always saw myself capable of handling linguistic problems. I actually enjoyed facing problems."

According to the $\mathrm{p}$ articipant, self-efficacy, which she de veloped during sev eral y ears of he $\mathrm{r}$ language learning, he lped her take more risks in u sing ne w structures and modifying the previously learned forms in or der to be more creative and independent in us ing 1 anguage. $S$ he $\mathrm{s}$ tated that $\mathrm{s}$ he gained confidence in using language in an innovative and dynamic way.

\section{Private speech}

Private speech among learners also has a significant role in language learning (Jina, 2008). According to consensus of the participants, in an ESL c ontext, role-playing i mproved their English 1 anguage through expressions that demonstrate relief or pleasure or that indicate anxiety and insecurity. Roleplaying served as an emotional support that promoted psychological distancing and self-control to express the frustration of language learning. According to one of the participants,

"Private speech gave me the chance to self-regulate myself before I am corrected by the teacher. It gave more self-confidence to speak up since I was more certain and conscious about the accuracy of the structures I was going to say in class. The element of repetition and analysis of grammatical structures al so helped me keep words or structures in my memory for a longer period of time."

The participants also affirmed that private speech helped their self-regulate herself before they uttered linguistic structures. They made us e of repetitions and monologues to check her accuracy of thought before they spoke a word. They told that they mostly used such a skill in situations which they faced difficulties with the pronunciation and grammatical structure of a sentence.

Private speech, according to the participants, formed an indispensable part of their language learning, especially the early stages of it. One of the participants who is from Turkey who has been living in the US for a long time stated,

"I r emember I us ed to repeat what my teachers said very qui etly, especially when my teachers were introducing the vocabulary which was hard to pronounce. Even before I uttered any g rammatical or 1 exical s tructure, I w hispered the w ords o $r$ se ntences first. These w hispering and repetition of st ructures in the ear ly st ages of 1 anguage 1 earning turned to more inner speech in more advanced levels of learning English. In higher levels 
and even now I think about what I am going to say and then I put thoughts into words. This does not always the case. Sometimes the thinking and speaking were simultaneously occurring."

Therefore, private speech is an important factor within the sociocultural perspective.

\section{Conclusion and Implication}

Learning a s econd language is a long and complicated process that involves all aspects of a language such as lexicon, grammar, reading, writing speaking etc. In this process, some language learners are, not surprisingly, more successful than others depending on many factors. However there are some crucial factors influencing the success in language learning. In the current study, some of the central concepts of s ociocultural theory were investigated to determine their influences on the language learning process. These concepts include peer interaction and feedback, private speech, and self-efficacy. Twenty participants' answers to the questions in the interviews related with the sociocultural factors in question w ere a nalyzed to obt ain a $n$ ov erall pi cture of their ideas a nd thoughts ba sed on $t$ heir language learning experiences.

Considering the influence of peer interaction and feedback in the language learning process, the twenty participants expressed contradictory views. Peer interaction has a major influence on the language learning process of most of the participants whereas it has a minor influence for few participants. This difference may result from the interaction types. In the case of the participants, the way of interaction was student-teacher or teacher-student with few exceptions of interaction with peers. In language classes, it may be useful to increase the types of activities and tasks that provide more peer interaction. Such an approach can create the collaborative atmosphere in the language classroom, providing more interactive learning oppor tunities for the language learners. In terms of feedback, it is clear from the remarks of the participants that direct error correction made repeatedly by the teacher is not preferable since it discourages the student to participate in classroom activities. Therefore, language teachers should be careful about how and when they give feedback to the students since giving feedback means more than simply correcting students.

Self-efficacy can have a direct effect on language learning process since it forces individuals to reach their goals. The participants in the study have similar views on the effect of this socio-cultural concept on their language learning process. It is worth stating that negative teacher feedback has an undesired effect on the se lf-efficacy of $t$ he pa rticipants. It is therefore $r$ ational to claim that language teachers should be careful about the feedback they are providing to the students. Moreover, it is also the duty of $t$ he language t eachers to improve the self-efficacy be liefs of their students towards language learning. Private spe ech is ano ther $\mathrm{c}$ entral co ncept of socio-cultural $\mathrm{t}$ heory $\mathrm{t}$ hat affects languagelearning process. It is to some extent the inner-defensive-tool of the language learners. The participants in the study view private speech as a helpful tool in their language learning proces

\section{References}

Creswell, J. W. (1994). Research designs: Qualitative and quantitative approaches. Thousand Oaks, CA: Sage.

Creswell, J. W . (2003). Research design: Qualitative, quantitative, and $m$ ixed methods approaches (2nd ed.). Thousand Oaks, CA: Sage Publications.

Donato, R. (1994). Collective scaffolding in second language learning. In J. P. Lantolf, \& G. Appel (Eds), Vygotskian A pproaches to Se cond Language Research (pp. 33-56). N J: Ablex.

Flor, A. M. (2010). Does language learners benefit from classroom interaction? 
Lantolf, J. P. (2000). Sociocultural theory and s econd language learning / edited by James P. Lantolf. Oxford [Eng.]. New York : Oxford University Press, 2000.

Jina, L. (2008). Gesture and private speech in second language acquisition. Studies in Second Language Acquisition, 30(2), 169-190.

Sato, M., \& Lyster, R. (2012). Peer Interaction and Corrective Feedback for Accuracy and Fluency D evelopment: M onitoring, P ractice, a nd Proceduralization. Studies in Second Language Acquisition, 34(4), 591-626.

Swain, M. (1995). Three functions of output in second language learning. In G. Cook and

B. S eidhofer (eds.) Principles and pr actise in applied linguistics. Oxford, Oxford University Press.

Philp, J., Walter, S. \& Basturkmen, H. (2010). Peer Interaction in the Foreign Language Classroom: What Factors Foster a Focus on Form?. Language Awareness, 19(4), 261-279.

Ohta, A. (1995). Applying Sociocultural Theory to an Analysis of Learner Discourse: LearnerLearner Collaborative Interaction in the Zone of Proximal Development. Issues In Applied Linguistics, 6(2), 93.

Oxford, R . \& S hearin, J. ( 1994). Language le arning mot ivation: Expanding the the oretical framework. Modern Language Journal, 78, 12-28.

Wertsch, J.V. (1985). Vygotsky and the social formation of mind. Cambridge, MA: Harvard University Press.

Vygotsky, L. S . (1981). The d evelopment of hi gher forms of attention in childhood. In J . V.Wertsch, e d. The c oncept of ac tivity i $n$ So viet ps ychology. A rmonk, N Y: M .E. Sharpe, 189-239.

Vygotsky, L. S. (1962). Thought and language. Cambridge MA: MIT Press. 